\title{
La creación de relatos digitales no lineales como herramienta intercultural en el ámbito de la filología francesa
}

\author{
The creation of non-linear digital stories as an \\ intercultural tool in the field of French philology
}

\author{
Silvia Hueso Fibla \\ Universidad de Valencia \\ Silvia.hueso@uv.es
}

\begin{abstract}
This article focuses on the importance of gamification as a form of innovative teaching method in French Philology for our digital native students. The creation of serious games can encourage them, generating active participation and better academic results. In the context of TICE class in the UV LML Degree, we did workshops during the last two years for the creation of interactive fictions based on hypertexts with a tool called Twine. We are going to analyze the amazing results and give some didactic examples to implement this tool in the university classroom.
\end{abstract}

\section{Keywords}

gamification, Twine, interactive fiction, French Philology.

\begin{abstract}
Résumé
Cet article porte sur l'importance de la gamification en tant que méthode d'enseignement innovante en philologie française pour nos étudiants natifs du numérique. La création de serious games peut les encourager, générer une participation active et de meilleurs résultats scolaires. Dans le cadre de la classe TICE de LML à l'UV, nous avons réalisé des ateliers au cours des deux dernières années pour la création de fictions interactives basées sur des hypertextes avec un outil appelé Twine. Nous allons analyser les étonnants résultats obtenus et donner quelques exemples didactiques pour implémenter cet outil dans la formation universitaire.
\end{abstract}

Mots-clés: gamification, Twine, fiction interactive, Philologie Française. 


\section{Introducción: La gamificación en el aula de lengua y cultura francesas}

Il gioco si fa accompagnamento, complemento e parte della vita in generale. Adorna la vita e la completa, e come tale è indispensabile. È indispensabile all'individuo, in quanto funzione biológica, e è indispensabile alla collettività per il senso che contiene, per il significato, per il valore espressivo, per i legami spirituali e social che crea, insomma in quanto funzione culturale. Soddisfa a ideali di espresione e di vita collettiva. (Huizinga, 1967: 28)

Resulta ineludible hablar de gamificación y de serious games sin hacer referencia al Homo ludens de Johan Huizinga (1938) y al análisis del juego que realizó en su día y que añade al binomio homo sapiens y homo faber este tercer hombrecito que marca la importancia del juego como función humana y como herramienta cultural.

De Huizinga, pasamos a otra ineludile referencia cultural del mundo occidental como fue Mary Poppins que en 1964 dijo aquello de "a spoonful of sugar helps the medicine go down" (Carreras, 2017: 108) y que retoma el horaciano docere et delectare de la Epístola a los Pisones, que ya podemos rastrear en las Fábulas de Esopo y en las de La Fontaine.

Éste último, en su prólogo a la edición de 1668 subraya el valor didáctico de las fábulas, que eran tomadas como un género menor, pero que poseían "un certain charme, un air agréable qu'on peut donner à toutes sortes de sujets, même les plus sérieux" (La Fontaine, 2002:39). La misma edición, viene precedida de una dedicatoria al Delfín, en la que, explícitamente, habla de las fábulas como de divertimentos que encierran serias enseñanzas, cuya apariencia es pueril (en tanto son consideradas como un juego) pero que "servent d'enveloppe à des vérités importantes" (La Fontaine, 2002: 35).

En este mismo sentido horaciano o marypoppiano (como cada cual prefiera) los docentes actuales llevamos un tiempo planteándonos cómo interesar a un alumnado de nativos digitales, más acostumbrado ya a la pantalla que al papel y con más horas en el cuerpo de videojuego que de lectura, al que podemos llamar, con Rodríguez y Santiago (2015: 9), la generación G (de gamers).

Un alumnado que ya no puede seguir clases magistrales porque se aburre. Que necesita ser multi-estimulado con documentos de diversa índole y que necesita ser motivado con algo más que el mero "sacar buenas notas". Aquí es donde entra la idea de aplicar las dinámicas del juego al aula, en lo que conocemos como estrategias de gamificación ${ }^{1}$.

Al aplicar la dinámica del juego a la enseñanza en general y al aula de lengua y litera-

1 Acuñado por Nick Pelling en 2002, el término gamificación equivaldría al castellano ludificación (del latín ludus-ludi), aunque se suele utilizar más el primero. Karl M. Kapp define la gamificación como "using gamebased mechanics, aesthetics and game thinking to engage people, motivate action, promote learning, and solve problems" (2012: 10). Aplicado a la enseñanza, se trata de crear un sistema de juego que atrape al alumnado y le presente un desafío, con unas determinadas reglas, incluyendo niveles, premios, con una estética atractiva a nivel de diseño y que termine enganchando para que el alunado quiera más (quiera jugar más y seguir aprendiendo al mismo tiempo). 
tura francesas a nivel universitario, en particular, el nivel de atención del alumnado aumenta, el entusiasmo por la materia se ve incrementado y todo ello se refleja en las calificaciones. Como explica Oriol Ripoll, se pueden incluir en el aula todo tipo de juegos, tanto on-line como off-line: de mesa, de calle, de rol, de competición... ya que lo importante es "estimular la atención y la implicación de los individuos en las tareas que realizan" (Ripoll apud. Carreras, 2017: 109).

Algo tan simple como premiar la participación individual durante todo el curso a cambio de puntos canjeables por un porcentaje de la nota final o como realizar por grupos un concurso de montaje de vídeo sobre las obras explicadas en clase y regalar un detalle al equipo vencedor (además de mayor nota), aparecen como estrategias básicas de gamificación que sirven para aumentar el interés por la materia y ayudan a optimizar el aprendizaje en la nueva generación de jugadores nativos digitales.

Por una parte, tenemos estas dinámicas del juego aplicadas a la didáctica de una materia determinada y, por otra parte, existen los serious games que son juegos concretos con una finalidad no meramente lúdica (para nosotros, el aprendizaje de un elemento en particular del currículum pedagógico) y que Tania Fernández define como:

Una herramienta pedagógica que va más allá del entretenimiento para ofrecer un medio atractivo y apoyar el aprendizaje en un sentido amplio; ya sean juegos digitales, simulaciones, entornos virtuales, realidad/medios mixtos que proporcionan oportunidades para participar en actividades a través de relatos o historias sensibles, juegos o encuentros. (Fernández, 2017: 11)

Sendas distinciones pueden parecer artificiales porque en ocasiones sus fronteras son borrosas (Kapp, 2012: 16) y porque comparten muchos elementos comunes: detrás de ambas se halla una narrativa atractiva a modo de hilo temático, cierta personalización, un feedback inmediato que ayuda a estimular al alumnado, la idea del reto y desafío que promueva cierta competitividad y, por último, el premio final (Carreras, 2017: 113-114).

A pesar de ello, la distinción entre gamificación y serious game, nos sirve para hablar de una herramienta en concreto, twine, con la cual podemos crear relatos digitales no lineales y cuyo uso ha sido aplicado al aula de TICE del Grado de Lenguas Modernas y sus Literaturas (LML; maior de francés) de la UV los dos últimos cursos.

\section{Una herramienta diferente: Twine}

Aquellos que ya leíamos en los años 80 , conocimos una colección de libros juveniles llamada Elige tu propia aventura basada en lo que se conoce como hiperficción explorativa²

2 Susana Pajares subraya la diferencia entre la hiperficción explorativa, realizada por una sola persona, y la hiperficción constructiva que proviene del trabajo común de varias personas. Los juegos de rol, por ejemplo, serían una hiperficción constructiva en la que the master/narrador-a arbitra una historia en la que las demás 
o ficción interactiva (FI), en los cuales cabía la posibilidad de ir eligiendo opciones según avanzaba la historia, pues la instancia narrativa proponía al cabo de cada secuencia la posibilidad de tomar una decisión u otra como si fuéramos los propios personajes. Se establecían numerosas opciones de lectura, ya que la trama iba variando según se eligieran unas ramas de la historia u otras.

El lema de la colección era el siguiente:

Las posibilidades son múltiples; algunas elecciones son sencillas, otras sensatas, unas temerarias... y algunas peligrosas. Eres tú quien debe tomar las decisiones. Puedes leer este libro muchas veces y obtener resultados diferentes. Recuerda que tú decides la aventura, que tú eres la aventura. Si tomas una decisión imprudente, vuelve al principio y empieza de nuevo. No hay opciones acertadas o erróneas, sino muchas elecciones posibles. (Montgomery \& Granger, 1983: 1)

Estas obras iban claramente destinadas a un público juvenil e hicieron las delicias de toda una generación. La idea que se maneja al crear este tipo de obra es el hipertexto:

El hipertexto se compone de texto y de unos nexos ("links"), que conectan directamente con otros textos al ser activados, formando una red contextual sin principio ni fin, pues se puede saltar constantemente de unos textos a otros según se van escogiendo nuevas opciones de búsqueda. (Pajares, 1997)

Se trata pues de una estructura no secuencial que une textos, gráficos y diversas formas de información a través de enlaces y conexiones lógicas. Esta herramienta inestimable en la era digital, no ha surgido de la nada ni tampoco su aplicación a la escritura de ficción.

Cortázar en Rayuela (1963) ya exploró la idea de mezclar la narrativa con el juego ${ }^{3}$, indicando al final de cada capítulo el nombre de otro más lejano en un ir y venir que recuerda los viajes del lado de acá al lado de allá y que permite leer su obra de diversa forma: como una novela tradicional (de la primera a la última página); entrando en el juego propuesto por el autor (saltando de un capítulo a otro según sus indicaciones); o como gustes, pues te puedes equivocar e ir saltando como quieras de un capítulo a otro. Lo que resulta interesante en este tipo de narraciones es la ausencia de pasividad del lector: como tal, está obligados a tomar partido y elegir qué hacer, más allá de abrir la obra y cerrarla de golpe si le deja de interesar. La piedra de toque de estas propuestas se basa en la interactividad que implica una

participantes serían actrices y actores siguiendo ciertos elementos prefijados, pero con un guion flexible que pueden ir modificando a medida que juegan (the master/narrador-a no controla la historia). La cuestión es que las hiperficciones constructivas suelen carecen de intencionalidad estética y por ello se alejan del hecho literario, no así las explorativas, cuyo-a narrador-a controla la historia, a pesar de dar al-a la lector-a la posibilidad de múltiples opciones que los sitúan a ambos como elementos activos en la construcción textual (Pajares, 1997).

3 La propuesta narrativa de Cortázar no está lejos de la propuesta del OULIPO que arranca con Raymond Queneau, François Le Lyonnais, etc. en 1960 y cuyo espíritu se basa en la experimentación poética y el juego lingüístico. No en vano, allá por los años 70 los oulipianos invitaron a Cortázar al taller, lo que él rechazó porque no tenían similar posicionamiento político. 
comunicación en dos direcciones, típica de las tecnologías de la información y de la computación (Vázquez, 2019: 96).

La era digital ha visto multiplicarse las propuestas de FI, sobre todo en el ámbito anglosajón, ya que, como dice Hugo Labrande: " $90 \%$ de la production de fictions interactives est écrite en anglais. La majorité des auteurs et critiques de la fiction interactive parlent donc anglais, et la fiction interactive est principalement un genre anglophone" (Labrande, 2011). Son ficciones que en los años 80 gozaron de gran popularidad en el ámbito anglosajón y emergieron en otros ámbitos como el francófono ${ }^{4}$, donde tuvieron un declive en los 90 para volver a renacer a partir del año 2000. Desde dicha fecha, las historias interactivas se empezaron a traducir del inglés, aumentó su producción en otros ámbitos lingüísticos, se fueron generando bases de datos y otras iniciativas relacionadas con ellos.

Como ejemplos, tenemos en primer lugar el IFDB (Interactive Fiction Database ${ }^{5}$ ) que es el mayor catálogo en línea de historias interactivas donde los usuarios cuelgan de forma colaborativa nuevos juegos, críticas, recomendaciones etc. La mayoría del contenido viene de países anglófonos, pero sin dejar de lado las creaciones de otros ámbitos culturales.

En segundo lugar, el Club de Aventuras $A D\left(\mathrm{CAAD}^{6}\right)$ que es la comunidad hispanófona de juegos interactivos, en cuyo cibersitio aparecen secciones de noticias, de descarga de relatos y aventuras, enlaces a sus proyectos y a otras webs de aventuras. Se puede colaborar creando historias o traduciéndolas, ya que editan un fanzine en línea (SPAC 2.0). Ofrecen varias herramientas de creación de relatos interactivos (Superglús, AGE, Infsp6, InformATE...).

En último lugar, la Communauté francophone de fiction interactive ${ }^{7}$ que tiene un sitio dedicado a la FI francófona (o traducida al francés) en el cual se publican cada semana artículos sobre el tema, con una base de datos de juegos organizados por géneros (comedia, aventura, drama, fantasía, histórico...), varias herramientas para la creación de ficciones interactivas (Inform6, Inform 7, Ink, Undum, Raconteur...) y las bases para su concurso anual ${ }^{8}$.

Los elementos distintivos de este tipo de ficciones son el programa que genera el texto, el discurso narrativo, el ambiente simulado y la existencia de reglas del juego. Se hace necesaria la figura del interactor (término específico para aquellas personas que juegan en este tipo de historias) y el texto suele contener, además de palabras, gráficos, sonido y vídeo.

4 En torno a 1984 nacieron en Francia varias editoras de juegos como Froggy Software de Jean-Louis Le Breton y Fabrice Gille, Loriciels de Marc Bayle y Laurent Weill, ERE Informatique de Philippe Ulrich y Emmanuel Viau. Aunque no se dedicaban realmente a la FI, los primeros juegos que crearon contenían aventuras en modo texto con grafismos y se acercaban realmente al género (Labrande, 2001).

5 Se puede consultar en: https://ifdb.org/.

6 Se puede consultar en: https://www.caad.es/.

7 Se puede consultar en: http://www.fiction-interactive.fr/.

8 En este sentido, existe en ámbito hispanófono la Rayuela de arena, una gamejam (competición on-line de juegos narrativos) en la que cabe cualquier juego cuyo eje principal sea la narrativa. Es un evento que da pie a la publicación de conferencias, keynotes, artículos, tutoriales... que ayudarán a la creación y discusión en torno a los juegos. Se puede consultar en: https://itch.io/jam/rayuela-de-arena-2021. 
Aunque se suelen llamar "juegos", no necesariamente lo son, por tanto la palabra work es más adecuada para referirse a este tipo de interacciones (Montfort, 2003).

Según la implicación del/la interactor en el desarrollo narrativo, Marie-Laure Ryan definió cuatro niveles que van de la interactividad periférica que se limita a la exploración de la narración sin influir en el orden de lo narrado ni en la propia historia, hasta aquella basada en la creación de la historia en tiempo real (con ayuda del sistema), pasando por una interactividad en la que la usuaria está fuera de la narración, pero controla el orden de los contenidos o, finalmente, aquella en la cual se tiene libertad de exploración porque se crean variaciones en una historia predefinida:

The user play the role of a member of the storyworld, and the system grants him some freedo of action, but the purpose of the user's agency is to progress along a fixed storyline,and the system remains in firm control of the narrative trajectory. This type of interactivity is typical of computer game, such as: adventure games, shooters, mysterysolving games. (Ryan, 2005)

Tanto los relatos no-digitales de Elige tu propia aventura y Rayuela como la mayoría de FI digitales corresponderían a este tercer nivel de interacción, en el cual se tiene libertad de exploración dentro de las posibilidades aportadas por el-la enunciador-a de la historia. Pero en un sitio de tipo literario sobre un-a autor-a determinado-a, el hipertexto nos ofrece la posibilidad de interactuar en el segundo nivel de Ryan, es decir, una exploración de la narración en la que podemos variar el orden de los elementos que vamos explorando, aunque no generamos variaciones en el contenido de la historia.

Para la creación de relatos digitales no lineales, existe una herramienta de código abierto muy sencilla llamada Twine que se puede utilizar tanto en trabajos no ficcionales y ficcionales como en los serious games. Se basa en el uso de hipertextos y su punto fuerte es que, en la página de inicio, la disposición gráfica de los distintos hipervínculos aparece como un mapa mental que permite no perderse cuando la proliferación de opciones en nuestra historia comienza a aumentar considerablemente. Es una herramienta bien conocida por aquellas las personas que se dedican a explorar la narrativa digital no lineal.

\section{Taller de creación de relatos digitales no lineales (LML, UV, Filología Francesa)}

La idea de aplicar este tipo de relatos al aula de Lengua y Literatura francesas surgió inspirada por una iniciativa de la $\mathrm{RAE}^{9}$ en Twitter (2019) consistente en la creación de juegos lingüísticos que entremezclaban las narraciones ramificadas con los problemas de gramática y léxico del español. Estos juegos se caracterizaban por:

9 "Primera aventura para héroes lingüísticos": https://enclave.rae.es/blog/primera-aventura-para-heroes-linguisti$\cos [22 / 05 / 2021]$. 
- Brevedad y la sencillez de la trama: dado el limitado número de caracteres que Twitter permite publicar, el argumento de las historias debía ser mínimo, pero muy tentador para que el peso del contenido teórico que se intentaba transmitir no terminara con el objetivo principal que era divertir (docere et delectare).

- Objetivo didáctico basado en errores lingüísticos: la opción incorrecta contenía una explicación lingüística muy simple.

- Zasca: con bastante sentido del humor, además de una explicación del error se le añadía un zasca que podía ir desde la simple expulsión del juego (y vuelta a empezar), hasta el bloqueo de puertas que impiden continuar, pasando por diferentes tipos de heridas físicas que obligan al interactor a volver a la pantalla anterior. La cuestión es castigar con humor.

- Captatio: Puede haber una trama más o menos elaborada, mayor o menos contenido lingüístico, mayor o menos longitud... lo importante es que el trabajo enganche y que a través del viaje por estos juegos se aprenda algo y la gente se divierta, se pregunte qué va a pasar después.

A partir de ahí, mi compañera del departamento de Filología Francesa e Italiana de la UV, Elena Moltó, y yo, decidimos proponer en la asignatura TIC aplicadas a la lengua francesa un taller de creación de FI de contenido relacionado con nuestra especialidad, para que el alumnado aprendiera de forma básica algún elemento de lenguaje html, conociese este tipo de FI y desarrollara distintas aptitudes del MCERL, concretamente la expresión y comprensión escritas, además de ciertas competencias pragmáticas y sociolingüísticas.

En lo que al MCERL se refiere, al tratarse de una asignatura del segundo semestre del primer curso de LML, el alumnado presenta un nivel lingüístico bastante irregular, habiendo personas que han cursado sus estudios de primaria y secundaria en el Lycée français, mientras que otras, es el primer año que estudian la lengua francesa y apenas alcanzan el nivel A2. La asignatura se imparte en paralelo a Lengua Francesa 2, cuyos objetivos finales son la obtención de un nivel A2 o B1 preferiblemente, aunque por desgracia, no todo el alumnado consigue alcanzarlo al final de este primer curso. También se desarrolla paralelamente a la asignatura Literatura y cultura en lengua francesa $I$ en la cual se imparten contenidos de literaturas francófonas.

La propuesta en clase de TICE se adaptaba perfectamente a las competencias comunicativas y narrativas del MCERL correspondientes al nivel A2. En cuanto a la comprensión escrita, este nivel requiere que el alumnado sea "capaz de leer textos muy breves y sencillos", sepa "encontrar información específica y predecible en escritos sencillos y cotidianos, como anuncios publicitarios, prospectos, menús y horarios" y comprenda "cartas personales breves y sencillas" (MCERL, 2002: 30). Al tratarse de textos breves de contenido lingüístico y cultural con el que el alumnado está familiarizado por haberlo trabajado en las asignaturas que se desarrollan de forma paralela, un nivel A2 es largamente suficiente para la comprensión mutua de las FI creadas en el aula de TICE.

La expresión escrita correspondiente al nivel A2 exige ser "capaz de escribir notas y mensajes breves y sencillos relativos a mis necesidades inmediatas [...] escribir cartas 
personales muy sencillas; por ejemplo, agradeciendo algo a alguien” (MCERL, 2002: 30). Se adapta perfectamente al nivel del aula de TICE porque el alumnado, a pesar de cometer numerosos errores léxicos y gramaticales, tiene a su alcance herramientas de corrección textual que le permiten la creación de estas historias breves, además de poder utilizar las propias dudas y errores para hacer jugar al resto del grupo y aprender de ello.

Más allá de las competencias lingüísticas, los ejercicios creados con TWINE permiten desarrollar a habilidades sociolingüísticas, puesto que, a través de los textos, se recrean situaciones que les permiten utilizar expresiones habituales y fórmulas de tratamiento básicas, así como "responder a invitaciones y sugerencias, pedir y aceptar disculpas" (MERCL, 2002: 119); no obstante, lo más importante a mi entender, son las competencias pragmáticas que permite desarrollar la creación de FI lingüísticas, ya se deben tener en cuenta los contextos de uso, la coherencia y cohesión de los distintos apartados para seguir una secuenciación lógica de respuestas correctas e incorrectas, el modo de contar la historia o chiste y la capacidad de desambiguar enunciados en el contexto lúdico del zasca amigable.

Como parte de estas competencias pragmáticas, el MERCL especifica que se debe evitar "la oscuridad y la ambigüedad. Si desea desviarse de estos criterios [...] debería ser por una finalidad específica, y no debido a la incapacidad de cumplirlos" (MCERL, 2002: 120). Así pues, se trata de la capacidad del/de la interactor de detectar esas ambigüedades para darles la vuelta y seguir el camino lingüístico correcto que lleve al final del juego, aunque para los relatos digitales que se acercan más al storytelling que al serious game, esta desambiguación es menos necesaria.

Pero, ¿cómo se crean estas historias? Existen numerosos sitios en los que se explica la utilización de la herramienta, tanto en inglés como en francés y español ${ }^{10}$. Para crear una FI con Twine, basta con entrar al sitio del software y trabajar en línea o descargar la herramienta para poder salvaguardar las historias con mayor facilidad. La pantalla de inicio tiene un solo menú desde el que se puede cambiar la apariencia de la historia y exportarla a un fichero html.; desde aquí podemos observar las ramificaciones que irá adquiriendo nuestro Twine y con una codificación muy básica (doble corchete de apertura y cierre para cada nueva ramificación) empezar a forjar nuestro universo. Sólo tenemos que clicar en "añadir historia", titular nuestra FI y editar cada casilla.

Además del cambio de apariencia, ya que por defecto viene en letra blanca sobre fondo negro y letra azul para las opciones a elegir, podemos añadir imágenes, vídeos, gifs, sonidos en loop, links a otros sitios, etc. Aquí radica la única dificultad de la herramienta, ya que estas modificaciones sí se realizan en $\mathrm{html}$. dentro de la casilla que estamos editando ${ }^{11}$.

10 Algunos ejemplos son: la guía de usuario del sitio de Twine (http://twinery.org/wiki/twine2:guide); el de la Communauté francophone de fiction interactive que propone y explica el uso de Twine (http://www.fiction-interactive.fr/tutoriel-premier-jeu-en-twine/)o el del Instituto de Tecnologías Educativas Yo Profesor donde se explica cómo realizar una FI (https://yoprofesor.org/2018/09/14/crea-tu-primera-historia-interactiva-con-twine/).

11 Nótese que el profesorado proporcionó todos los códigos para que el alumnado sólo tuviera que sustituir un fragmento de la codificación por el de la imagen, sonido, vídeo... que escogiera. 
Una vez hemos realizado toda la edición, podemos exportarla desde el menú principal a un fichero web y subirla a Googledrive o Onedrive para utilizarlo como hosting de forma gratuita y exportar la IF a la web ${ }^{12}$ a través de DriveToWeb ${ }^{13}$. Nuestra IF está publicada y lista para que el resto disfrute jugando y aprendiendo.

\section{La experiencia con Twine. Algunos ejemplos}

Durante los dos cursos en los que se ha realizado el taller de creación de FI con Twine en el aula de TIC y en los que ambas profesoras hemos realizado serious games con dicha herramienta para utilizarlos en otras asignaturas de Filología Francesa, los resultados han sido realmente asombrosos.

Twine ha sido útil también en la creación de unidades didácticas que siguen el segundo nivel de interacción de que habla Marie-Laure Ryan (2005), consistente en explorar la historia variando el orden de los elementos, aunque no el contenido. En este sentido, creamos una unidad didáctica de la asignatura Literatura y Cultura en lengua francesa III, en la que se estudian las corrientes literarias y culturales de los siglos XVII y XVIII ${ }^{14}$.

Aunque no se trata de un juego ficcional, la unidad didáctica ha sido confeccionada con Twine y nos da la posibilidad de explorar, mediante los hipertextos, diferentes elementos del entorno y la obra de Tristan l'Hermite en el orden que prefiramos. Al ser la poesía el género que más se estaba trabajando en ese momento en dicha asignatura, observamos que en los textos literarios citados se multiplican de nuevo los hipertextos para analizar elementos concretos de la poética del autor. Otros hipertextos nos llevan a vídeos de youtube (sobre Gaston d'Orléans, Giambattista Marino), a artículos académicos (Sandrine Berregard sobre Le page disgracié), etc.

En el contexto de la asignatura Estudios lingüísticos en lengua francesa 1, que aborda tanto la Historia de la lengua como la gramática histórica, la compañera Elena Moltó creó un serious game a modo de vérification des acquis ${ }^{15}$.

Ya se trata de una FI que se adapta al tercer nivel de interacción del que habla Ryan, pues el/la interactor tiene cierta libertad de acción para equivocarse y recibir el zasca, dentro de una historia pre-fijada en la que las buenas respuestas son las que te llevan al final del juego. Lo característico de este Twine es que además de contener las preguntas del juego, revisa todos los contenidos históricos estudiados en clase, desde la fecha del inicio de la romanización de la Galia, hasta la prohibición de las lenguas regionales, pasando por el matrimonio d'Aliénor d'Aquitaine con el duque de Normandía (futuro Enrique II de Inglaterra). Así pues, el contenido teórico resulta mucho mayor en porcentaje que el mero juego.

12 A la hora de hacer público el fichero, no debemos olvidar activar los permisos para compartir con toda la web.

13 Se puede consultar en: https://drv.tw/.

14 Podemos visitar la unidad didáctica en: https://xcif5thyhck2cwm1zybcua-on.drv.tw/tristan\%201'Hermite.html.

15 Podemos acceder desde este link: http://bit.ly/moltoe. 
En los talleres propuestos en clase de TIC y cuyos resultados iban a ser evaluados ( $5 \%$ de la nota final), el alumnado ha creado juegos lingüísticos y, sobre todo, IF con una finalidad lúdica para ejercitar la expresión escrita y las competencias pragmáticas. A la hora de realizar una valoración de los resultados obtenidos, a las competencias comunicativas y narrativas de las que hemos hablado anteriormente, del Moral, Villalustre y Neira (2016: 27) añaden la competencia digital, basada en la "habilidad para la búsqueda, selección, registro y tratamiento de la información, unida al dominio de lenguajes, técnicas y estrategias propias de los diferentes soportes, tales como el audiovisual, digital o multimedia". El uso de la propia herramienta que requiere cierta destreza para la inserción de imágenes, vídeos, sonidos y gifs, para cambiar el formato de la historia, crear ramificaciones y publicar los juegos, pone en evidencia esta competencia digital.

El estudio metodológico de los relatos digitales de del Moral, Villalustre y Neira (2016), nos ha proporcionado un modelo de en la que se contemplen tanto las competencias comunicativa y narrativa como la competencia digital, y que hemos adaptado a las necesidades de las IF con Twine:

\begin{tabular}{|c|c|}
\hline Dimensión & Indicadores \\
\hline \multirow{5}{*}{$\begin{array}{l}\text { 1. Competencia } \\
\text { comunicativa }\end{array}$} & 1.1. Elaboración escrita de la narración \\
\hline & 1.2. Uso de vocabulario adecuado \\
\hline & 1.3. Corrección gramatical y ortográfica \\
\hline & 1.4. Utilización correcta de notaciones gráficas (puntuación) \\
\hline & 1.5. Registro lingüístico adecuado (cuento, chiste, zasca...) \\
\hline \multirow{5}{*}{$\begin{array}{l}\text { 2. Competencia } \\
\text { narrativa }\end{array}$} & 2.1. Inclusión armónica de los puntos de inflexión del relato \\
\hline & 2.2. Coherencia interna (presentación, nudo y desenlace) \\
\hline & 2.3. Construcción de personajes \\
\hline & 2.4. Resolución creativa de la trama \\
\hline & 2.5. Intención comunicativa visible (moraleja, denuncia, reflexión...). \\
\hline \multirow{5}{*}{$\begin{array}{l}\text { 3. Competencia } \\
\text { digital }\end{array}$} & 3.1. uso adecuado de las aplicaciones informáticas y sus herramientas \\
\hline & 3.2. estructuración cuidada del proyecto \\
\hline & 3.3. cohesión del sonido con la narración \\
\hline & 3.4. selección adecuada de imágenes \\
\hline & 3.5. Publicación del proyecto en libre acceso \\
\hline
\end{tabular}

Esta rúbrica nos ha permitido valorar de forma objetiva los trabajos creados en el taller, algunos de los cuales presentamos a continuación. 


\subsection{Serious games de contenido lingüístico con Twine}

Entre los serious games, el ejemplo aportado por la docente para que pudieran comprender los fundamentos del juego ha sido una historia que trabajaba la homonimia en francés y que no se fundamentaba en la dinámica de cuestión y respuesta buena/mala, sino en frases escritas correcta e incorrectamente que llevaban a continuar el juego o a morir en el intento. El punto cómico del juego eran las barbaridades a las que se sometía al personaje principal (interactor) si cometía un simple error de gramática.

\begin{tabular}{ll}
\hline Título & Le Boucher et sa fille \\
\hline Autora & Silvia Hueso (docente) \\
\hline Tipología & Serious Game (Twine) \\
\hline
\end{tabular}

\begin{tabular}{|c|c|}
\hline Dimensión & Indicadores \\
\hline \multirow[t]{5}{*}{1.} & $\begin{array}{l}\text { 1.1. Trama en la cual la hija vegana de un carnicero intenta escapar a las ame- } \\
\text { nazas de su cruel padre adoptivo. }\end{array}$ \\
\hline & 1.2. Utilización del argot juvenil en consonancia con los personajes. \\
\hline & $\begin{array}{l}\text { 1.3. No aparecen errores gramaticales, aparece algún calco del español. Juego } \\
\text { a través de la homofonía. Las palabras incorrectas están utilizadas expre- } \\
\text { samente para confundir al/a la interactor. }\end{array}$ \\
\hline & 1.4. Corrección en las notaciones gráficas. \\
\hline & 1.5. Lenguaje familiar, comicidad acentuada, segundo grado e ironía.. \\
\hline \multirow[t]{5}{*}{2.} & $\begin{array}{l}\text { 2.1. La narración presenta momentos álgidos, cambios de tensión y efectos de } \\
\text { sorpresa. }\end{array}$ \\
\hline & 2.2. Narración coherente \\
\hline & $\begin{array}{l}\text { 2.3. Narración con pocos personajes que no evolucionan mucho dada al breve- } \\
\text { dad pero que poseen características propias que los individualizan. }\end{array}$ \\
\hline & 2.4. Creatividad elevada. \\
\hline & 2.5. Evidente intención de denuncia del especismo. \\
\hline \multirow[t]{5}{*}{3.} & 3.1. Uso adecuado de la herramienta \\
\hline & $\begin{array}{l}\text { 3.2. Presentación con cambio de formato (blanco / magenta), funcionamiento } \\
\text { de links e imágenes. }\end{array}$ \\
\hline & 3.3. Este proyecto carece de sonido. \\
\hline & 3.4. Imágenes que se corresponden con lo narrado \\
\hline & $\begin{array}{l}\text { 3.5. Ningún problema para acceder al proyecto a través del link proporciona- } \\
\text { do. https://xcif5thyhck2cwm1zybcua-on.drv.tw/le\%20boucher\%20et\%20 } \\
\text { sa\%20fille.html }\end{array}$ \\
\hline
\end{tabular}


Si nos fijamos en los serious games del alumnado, cabe destacar un trabajo titulado Scape Room Gramatical creado durante el segundo año del taller, en que se proponían cuestiones de gramática para poder salir de la casa en el que el/la interactor, junto con dos amigos, había quedado atrapado. La mayoría de las cuestiones hacía hincapié en la conjugación de verbos irregulares, el juego no presentaba demasiada complejidad, aunque la herramienta fue utilizada con éxito.

\begin{tabular}{ll}
\hline Título & Scape Room Gramatical \\
\hline Autora & Belén Clara (estudiante) \\
\hline Tipología & Serious Game (Twine) \\
\hline
\end{tabular}

\section{Dimensión Indicadores}

1. $\quad 1.1$ La narración no presenta gran complejidad, ni tiene intención de estilo.

1.2 Algunos errores de vocabulario (la joue, meurtres, agiterait, muerez, par ma partie...). Por lo demás, nivel adecuado al estilo del juego.

1.3. Algunos errores gramaticales en el uso de formas verbales (subjuntivo en lugar de presente Paula trouve un papier qui contienne le suivante message, fissez...), género gramatical (Quelle est le participe, droit en lugar de droite), preposiciones (à la, entre, par ma partie), ausencia de artículo (dont titre), etc. El juego trata sobre todo de responder cuestiones sobre la conjugación verbal: participe passé du verbe mettre, deuxième personne plurielle du verbe vouloir...

1.4. Ningún problema de puntuación.

1.5. No hay gran uso de recursos cómicos ni de zascas divertidos; no obstante, el nivel lingüístico es adecuado.

2. 2.1. El relato no presenta gran complejidad narrativa; se trata de un scape room a través de cuestiones gramaticales en el cual el/la interactor y dos amigos deben resolverlas para salir de la casa donde están atrapados.

2.2. Es un relato coherente, no presenta gran complejidad.

2.3. No se desarrolla la construcción de personajes en el relato.

2.4. Poca creatividad.

2.5. La intención única es el aprendizaje gramatical.

3. 3.1. Perfecto uso de la herramienta, inserción de gifs, imágenes etc. formato mejorado en verde mar.

3.2. No hay errores en el formato de la historia, pero, al no haber utilizado el corrector de gramática, el proyecto presenta errores importantes

3.3. Inserción de loops de audio en consonancia con la historia.

3.4. Imágenes en relación a la intriga.

3.5. Sin problemas en la publicación vía DriveToWeb. https://xcif5thyhck2cwm1 zybcua-on.drv.tw/Scape\%20room\%20gramatical.html 


\subsection{Ficciones interactivas}

Otro detalle que hemos podido observar tras realizar el taller es que nuestro alumnado disfruta mucho más creando historias de ficción pura que integrando contenidos gramaticales. Les resulta algo complejo, teniendo apenas un nivel A2, inventar historias de ficción en francés. A pesar de ello, los resultados obtenidos en las FI son realmente geniales, aunque nos vamos a limitar a analizar solamente los mejores ejercicios.

El primer ejercicio se titula Il était une fois... y retoma la leyenda china de Mulan dando la posibilidad de explorarla desde el personaje femenino o masculino. Aporta una mirada de género bastante interesante, está muy cuidado desde el punto de vista estético, tiene una extensión considerable que muestra el placer por la escritura de la alumna y es, en general, un trabajo satisfactorio.

\begin{tabular}{ll}
\hline Título & Il était une fois... \\
\hline Autora & Ana María Mateo (alumna) \\
\hline Tipología & Ficción Interactiva \\
\hline
\end{tabular}

\section{Dimensión Indicadores}

1. 1.1. La alumna retoma una leyenda china y se complace en la narración de la historia que tiene su propio estilo.

1.2. La utilización del vocabulario es correcta, en un tono y registro neutros muy adecuados.

1.3. Algunas faltas de gramática, por ejemplo, en el género gramatical ( $s a$ identité) pronombres COD, COI (lui écouter), preposiciones-partitivos (pris de temps), locuciones conjuntivas (bien si)... por lo demás, el relato es correcto desde el punto de vista gramatical.

1.4. Puntuación correcta.

1.5. El tono es serio, no hay puntos de humor.

2. 2.1. El relato sigue una progresión ascendente, su desarrollo es armónico y la trama es lógica. Se trata de la leyenda china de Mulán, que narra la participación de la joven en la guerra, transgrediendo los roles de género tradicionales.

2.2. La trama permanece con lógica a pesar de las ramificaciones, inexistentes en la leyenda original.

2.3. Interesante construcción que retoma la del relato original, a la vez que lo moderniza.

2.4. Las ramificaciones aportan originalidad a la trama, pero sólo se retoma la leyenda original.

2.5. Es evidente la intención de denuncia de la inmovilidad de los roles de género tradicionales de la alumna. 


\begin{tabular}{ll}
\hline Dimensión & Indicadores \\
\hline 3. & $\begin{array}{l}\text { 3.1. La herramienta ha sido utilizada correctamente, pese a algunas dificulta- } \\
\text { des con el programa a la hora de insertar imágenes. El formato de origen }\end{array}$ \\
& ha sido modificado a fondo blanco sin recuadro. \\
& 3.2. El proyecto es simple y elegante. \\
& $\begin{array}{l}\text { 3.3. El proyecto no tiene loops de sonido. } \\
\text { 3.4. Adecuación total de fotogramas del film de Disney y de breves vídeos del } \\
\text { mismo. }\end{array}$ \\
& $\begin{array}{l}\text { 3.5. La alumna también tuvo dificultades para compartirlo con GoogleDrive, } \\
\text { pero finalmente, el proyecto está en abierto. } \\
\text { https://xcif5thyhck2cwm1 zybcua-on.drv.tw/Il\%20\%C3\%A9tait\%20 } \\
\text { une\%20fois....html }\end{array}$ \\
\end{tabular}

El segundo ejercicio que vamos a analizar se titula "Survie dans une île déserte" y tiene un tono totalmente diferente al primero, ya que abandona la seriedad de la leyenda para adquirir la comicidad y la broma del mero juego de supervivencia. El juego avanza a través de preguntas básicas de supervivencia y las imágenes, los gifs, el sonido y las ocurrencias de la creadora aportan ese tono jocoso que hace que sea exitoso, a pesar de los numerosos errores léxicos y gramaticales que presenta.

\begin{tabular}{ll}
\hline Título & Survie dans une île déserte \\
\hline Autora & Gemma Esteban (alumna) \\
\hline Tipología & Juego de supervivencia/ ficción interactiva \\
\hline
\end{tabular}

\begin{tabular}{ll}
\hline Dimensión & Indicadores \\
\hline 1. & $\begin{array}{l}\text { 1.1. La narración no es compleja. El/la interactor protagoniza esta historia no } \\
\text { lineal en la cual debe sobrevivir en una isla desierta haciendo una cabaña, } \\
\text { buscando agua y comida, haciendo fuego, etc. }\end{array}$ \\
& $\begin{array}{l}\text { 1.2. Numerosos errores de vocabulario (chauf, influie, vague, invent, feau, bag- } \\
\text { ner...). Por lo demás, el vocabulario es adecuado al contexto de uso. }\end{array}$ \\
& $\begin{array}{l}\text { 1.3. Numerosos errores gramaticales, por ejemplo, uso de relativos (qui faire), } \\
\text { uso de pronombres personales de cortesía alternados con la no cortesía, } \\
\text { perífrasis verbales (avez de choisir), conjugación (mourriras), pronom- } \\
\text { bres átonos (protéger-toi)... }\end{array}$ \\
& $\begin{array}{l}\text { 1.4. Correcta puntuación. } \\
\text { 1.5. El tono es humorístico, con numerosas ironías y zascas al tomar la opción } \\
\text { incorrecta. }\end{array}$ \\
\hline
\end{tabular}




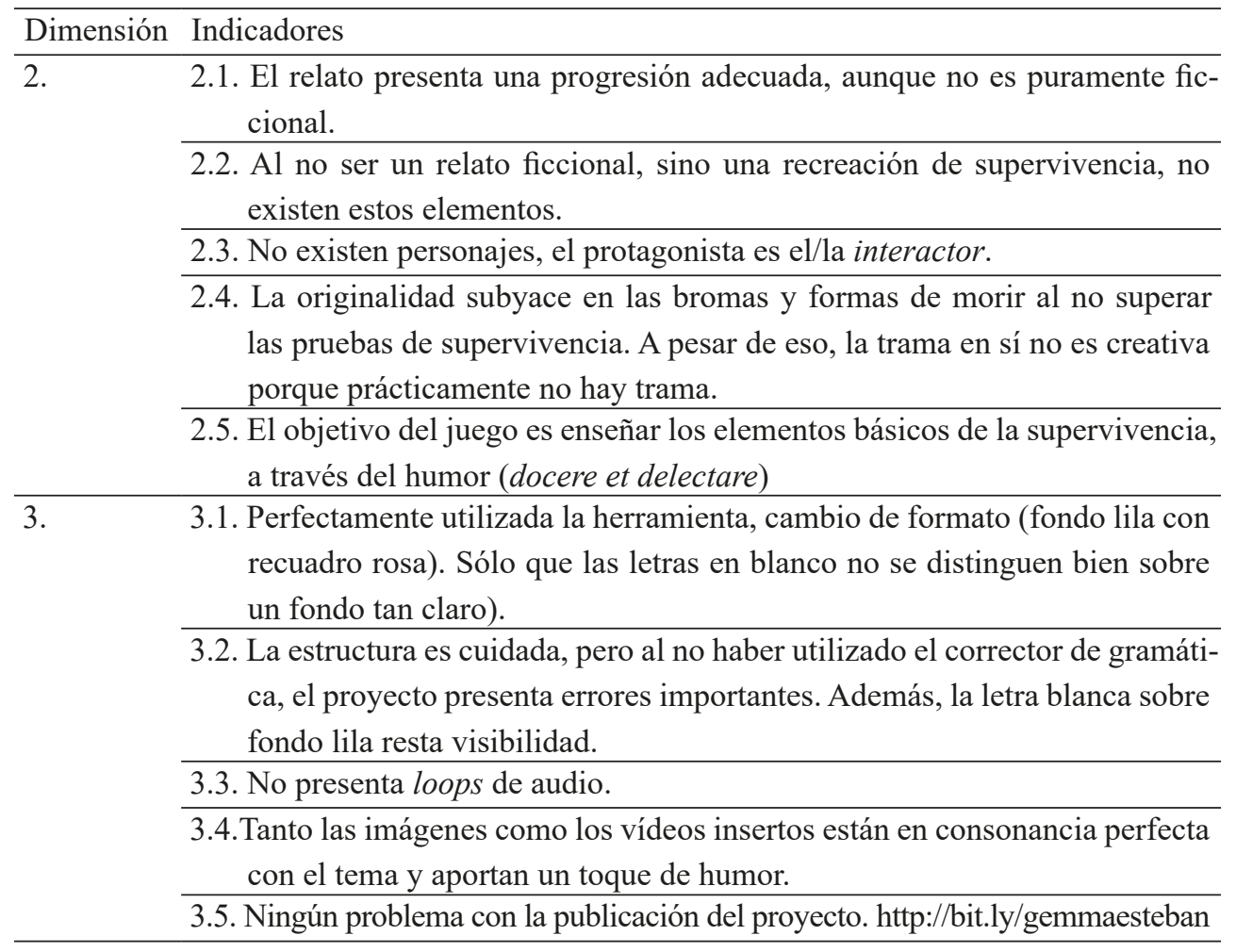

He aquí otro tipo de IF que retoma el mito de Perseo enfrentándose a Medusa con una intención didáctica (revisar la mitología clásica). Este tercer ejercicio, al haber sido creado por una alumna francófona, carece de los anteriores problemas léxicos y gramaticales; la alumna ha podido hacer hincapié en los elementos digitales que han dado lugar a un resultado asombroso porque se ha introducido una imagen de la Acrópolis como fondo de la historia.

\begin{tabular}{ll}
\hline Título & Persée et Méduse \\
\hline Autora & Aude Marchand (alumna) \\
\hline Tipología & Ficción Interactiva de tema mitológico \\
\hline
\end{tabular}

\begin{tabular}{|c|c|}
\hline Dimensión & Indicadores \\
\hline 1. & $\begin{array}{l}\text { 1.1. Ningún problema en la elaboración de la narración que presenta las etapas } \\
\text { de la búsqueda de Medusa por parte de Perseo: la ayuda de Hermes, de las } \\
\text { ninfas, las Gorgonas, el enfrentamiento con Medusa y, finalmente, con su } \\
\text { padre, el rey Polidectes. }\end{array}$ \\
\hline & 1.2. Vocabulario adecuado, nivel familiar. \\
\hline
\end{tabular}




\begin{tabular}{ll}
\hline Dimensión & Indicadores \\
\hline 1.3. A pesar de ser francófona, la alumna alterna los pronombres personales \\
tu y vous, lo cual genera cierta confusión en la historia porque se dirige a \\
Perseo, el/la interactor, de forma diferente cada vez (ej. vous aider à com- \\
pléter ta mission), también comete errores de concordancia elles ont un \\
seul oeil qui leur permettent. Por lo demás, la historia está perfectamente \\
elaborada a nivel lingüístico.
\end{tabular}

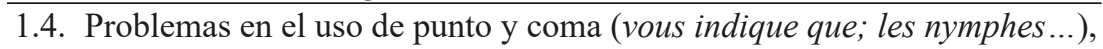
mayúscula/minúscula (Méduse/méduse).

1.5. Ningún elemento cómico, el relato mítico se queda en un registro neutro.

2. 2.1. Como en la leyenda clásica, el relato tiene sus idas y venidas en relación a los enfrentamientos del héroe con las pruebas (otros personajes).

2.2. Sigue las pautas de la narración, con la presentación de la problemática de Perseo, el nudo que son las pruebas y el desenlace que es el enfrentamiento final con el padre.

2.3. Personaje sin complejidad por tratarse de un héroe mitológico cuya psique no se puede explorar más allá, dadas las dimensiones del relato.

2.4. La creatividad se basa en las ramificaciones que va adquiriendo el relato. Al retomar el mito, no presenta una resolución original.

2.5. No hay una moraleja, la intención es el aprendizaje a través del juego del mito de Perseo y funciona perfectamente.

3. 3.1. Buen uso de la herramienta, el formato es realmente bello con la imagen de fondo de la Acrópolis y el recuadro en azul claro. La letra blanca no resalta suficiente sobre fondo azul

3.2. A nivel estético es un proyecto conseguido y muy cuidado.

3.3. No se aprecia si hay sonido porque el proyecto no está publicado.

3.4. Imágenes muy adecuadas. No podemos decir si hay gifs porque no está publicado.

3.5. Imposible acceder al proyecto fuera de la herramienta. La alumna presentó capturas de pantalla.

El cuarto ejercicio titulado Epilogue Amalfitano presenta una narración muy simple que realiza guiños a la literatura latinoamericana y a la obra de Roberto Bolaño concretamente. Los toques humorísticos están políticamente marcados, las imágenes, gifs y loops de audio también aportan toques de comicidad, pese a lo cual, resulta un ejercicio pobre. 


\begin{tabular}{|c|c|}
\hline Título & Epilogue Amalfitano \\
\hline Autora & Gerardo Dieterlen (alumno) \\
\hline Tipología & Ficción Interactiva \\
\hline Dimensión & Indicadores \\
\hline \multirow[t]{5}{*}{1.} & $\begin{array}{l}\text { 1.1. Amalfitano, personaje de Roberto Bolaño, se ha escapado de un libro y es } \\
\text { perseguido por la policía literaria, debe recorrer un sencillo camino en que } \\
\text { responde un par de preguntas sobre literatura de América Latina. Las ra- } \\
\text { mificaciones corresponden a las direcciones en que ha de seguir su camino. } \\
\text { En muy simple. }\end{array}$ \\
\hline & 1.2 Vocabulario correcto, nivel común. \\
\hline & $\begin{array}{l}\text { 1.3. Algunos errores de gramática en el uso de partitivos (d'argent) y el género } \\
\text { gramatical (droit). Por lo demás, la narración es correcta. }\end{array}$ \\
\hline & 1.4. Sin problema alguno de puntuación. \\
\hline & 1.5. Registro bastante neutro con algunos toques humorísticos. \\
\hline \multirow[t]{5}{*}{2.} & 2.1. El relato es tan simple que no presenta puntos de inflexión. \\
\hline & 2.2. Tampoco hay mucho desarrollo. \\
\hline & 2.3. Ningún desarrollo de los personajes. \\
\hline & $\begin{array}{l}\text { 2.4. Ninguna creatividad en la trama, más allá de los gifs, imágenes y guiños } \\
\text { humorísticos. }\end{array}$ \\
\hline & $\begin{array}{l}\text { 2.5. Quizás la intención sea señalar varios autores literarios que el autor del } \\
\text { trabajo considera pésimos. }\end{array}$ \\
\hline \multirow[t]{5}{*}{3.} & $\begin{array}{l}\text { 3.1. El trabajo no presenta ninguna pega, ya que la aplicación ha sido utilizada } \\
\text { correctamente. }\end{array}$ \\
\hline & $\begin{array}{l}\text { 3.2. Alunas de las opciones no presentan imágenes ni audio, con lo cual a ratos } \\
\text { resulta pobre. }\end{array}$ \\
\hline & 3.3. Los audios corresponden con la narración. \\
\hline & 3.4. Uso de imágenes adecuado y con guiños humorísticos. \\
\hline & $\begin{array}{l}\text { 3.5. Ningún problema en la publicación. https://bjk4qebrtkbktrdxgl9gsa-on. } \\
\text { drv.tw/Epilogue\%20Amalfitano.html }\end{array}$ \\
\hline
\end{tabular}

Hemos dejada par el final el que podemos considerar el mejor ejercicio del curso 2019-2020: una ficción interactiva titulada La boite que presenta dos ramificaciones principales, una de las cuales se inspira en la leyenda de la caja de Pandora y en la lucha contra algunos monstruos de la mitología clásica (el/la interactor debe vencerlos respondiendo cuestiones de ingenio) y la segunda se acerca más a las circunstancias actuales de la pandemia pero enlazándola con la presencia de los dioses del Olimpo (Hermes, concretamente). Se trata de la trama más elaborada y del ejercicio en general más completo porque las tres competencias están muy igualadas. 


\begin{tabular}{ll}
\hline Título & La boîte \\
\hline Autora & Nerea Cebrián (alumna) \\
\hline Tipología & Ficción Interactiva \\
\hline
\end{tabular}

\begin{tabular}{ll}
\hline Dimensión & Indicadores \\
\hline 1. & $\begin{array}{r}\text { 1.1. La narración es totalmente original, incorpora monstruos mitológicos con- } \\
\text { tra los que el/la interactor debe luchar (como protagonista de la historia } \\
\text { que es) y la caja de Pandora de donde salen. También hace referencia a la }\end{array}$ \\
& $\begin{array}{l}\text { pandemia. } \\
\text { 1.2. El lenguaje es correcto, un tono jovial y un nivel común. }\end{array}$ \\
& $\begin{array}{l}\text { 1.3. La composición apenas muestra errores de este tipo. Alguna confusión con } \\
\text { el uso del tratamiento de cortesía (tu/vous) y las concordancias (boîte-le }\end{array}$ \\
& \begin{tabular}{l} 
voir). \\
\hline 1.4. La puntuación está utilizada de forma impecable.
\end{tabular} \\
\hline 1.5. El tono es jovial, algunas ironías y guiños al presente covid-19. \\
2.1. Las ramificaciones marcan los propios puntos de inflexión. El relato pre- \\
senta dos caminos principales y en ambos casos el/la protagonista debe en- \\
frentarse a personajes mitológicos: la Manticora, por una parte, o la Hidra, \\
la Esfinge, Medusa y Pegaso, por otra parte.
\end{tabular}

2.2. La historia tiene los 3 elementos e incluye, en el desenlace de una de las ramificaciones principales, la confusión entre sueño y realidad.

2.3. No hay gran profundidad en la construcción de los personajes. La narración se centra más en la acción que en la descripción.

2.4. Es un relato bastante creativo que juega con la novela Percy Jackson y los dioses del Olimpo (2005) de trasfondo (con toda la saga).

2.5. No hay una moraleja visible, aunque el relato en todo momento castiga la cobardía e inacción y premia la valentía y el arrojo.

3. 3.1. La herramienta ha sido utilizada perfectamente. El formato de la historia, modificado (salmón con recuadro blanco).

3.2. La alumna ha añadido pequeños iconos para reforzar lo expresado en la historia. Funcionamiento correcto de todas las imágenes, gifs, vídeos y clips de audio que también refuerzan lo expresado.

3.3. Numerosos sonidos en loop con total cohesión.

3.4. Las imágenes están en perfecta relación con los elementos del relato.

3.5. Ningún problema en la publicación del proyecto. https://xcif5thyhck2cwm1zybcua-on.drv.tw/La\%20bo\%C3\%AEte\%20 (Twine\%20Nerea).html 


\section{Análisis comparativo de los resultados obtenidos}

Según podemos observar en la tabla (anexo 1), el análisis comparativo de los resultados muestra claramente que el alumnado no tiene ningún tipo de problema con el uso de esta herramienta, su problema viene del lado de las competencias comunicativas y narrativas.

A pesar de haber realizado el taller en clase de TICE, sabiendo que debía ser evaluado y disponiendo de ordenadores abiertos a red donde podía utilizar herramientas de corrección de ortografía y gramática, el alumnado sigue cometiendo errores que con este tipo de corrector podían ser paliados.

Otra cuestión es la falta de creatividad de muchos de los trabajos presentados. No sólo se han evitado las historias de contenido lingüístico (1/6), sino que, a la hora de crear relatos, el alumnado se inspira en otros ya existentes (mitos y leyendas, 3/6) o se va por la tangente creando juegos de poquísima complejidad narrativa. La ausencia total de elaboración de los personajes también es evidente, ya que prácticamente ninguno de los trabajos (1/6) presentaba matices en la construcción psicológica de los personajes (la brevedad de la extensión de los relatos no es un impedimento para que ésta exista).

Por tanto, para próximos talleres de este tipo las consignas deberían ser más estrictas en cuanto a la temática, ya que quizás se ha dejado demasiada libertad para escoger el tema y ello sea problemático para el alumnado. En este sentido, una nueva rúbrica ha sido ideada para paliar las deficiencias de los relatos en futuras ediciones:

\begin{tabular}{|c|c|}
\hline Tipología & $\begin{array}{l}\text { - Serious game } \\
\text { - Interactive fiction } \\
\text { - Unidad didáctica }\end{array}$ \\
\hline Competencias comunicativas & $\begin{array}{l}\text { - Adecuación léxica } \\
\text { - Uso de corrector de ortografía y gramática } \\
\text { - }(5 \text { faltas=trabajo suspenso) } \\
\text { - Coherencia en el uso de determinado nivel lingüístico }\end{array}$ \\
\hline Competencias narrativas & $\begin{array}{l}\text { - Necesidad de un hilo conductor } \\
\text { - Desarrollo de los personajes } \\
\text { - Coherencia y cohesión textual } \\
\text { - + zasca amigable }\end{array}$ \\
\hline Competencias digitales & $\begin{array}{l}\text { - Uso de imágenes } \\
\text { - Gifs } \\
\text { - Vídeos } \\
\text { - Loops de sonido } \\
\text { - Cambio de formato original de la historia } \\
\text { - Mínimo: } 10 \text { ramificaciones principales }\end{array}$ \\
\hline
\end{tabular}


Por otro lado, a pesar del éxito en el uso de la herramienta, es necesario dejar constancia de las dificultades con las que nos encontramos en el taller el curso 2019-2020. Al haber dado demasiado poco tiempo para realizar los ejercicios del taller el primer año, en el segundo año, dentro del cronograma estimativo de la materia, se le dedicaron dos sesiones (cada una de cuatro horas). Justo llegó la pandemia en dichas sesiones y la explicación de la herramienta fue exitosa pero la resolución de los problemas que poseía el alumnado no pudo ser realizada con éxito porque el proceso creativo del trabajo no podía hacerse de forma presencial, viendo dónde estaba el error.

Algunos de los problemas que tuvo el alumnado fueron:

- Dificultades para insertar imágenes, vídeos, gifs y loops. A pesar de proporcionarles los links para insertar sus enlaces, hubo numerosos errores de este tipo.

- Dificultades para publicar la historia. El hosting inicialmente asociado a Twine (filome.la) desapareció este segundo año y para publicar desde DriveToWeb, a la hora de hacer público el documento html, siempre había algún error en los pasos que seguía el alumnado que, al no estar delante observando el proceso, era complicado solucionar.

- Cambios de navegador que incompatibilizaban las historias.

- Problemas con MAC.

- Pérdida de historias por no haberlas guardado bien en una llave USB (los ordenadores de la UV no son de última generación).

A pesar de ello, todos los trabajos pudieron editarse (aunque fuera en formato básico); los que no pudieron ser publicados por el alumnado, lo fueron por el profesorado; la mayoría de ellos, a pesar de los errores y como hemos visto, dieron resultados excelentes y sus creadores/as quedaron realmente satisfechos/as con los resultados obtenidos y el aprendizaje resultante.

\section{Conclusiones}

En el contexto actual, la docencia universitaria debe adecuarse a un alumnado de nativos digitales y gamers para poder realizarse de forma exitosa. Las clases magistrales ya no funcionan y la dinámica del juego debe incorporarse al aula para que los contenidos sean asimilados correctamente. Un aula participativa que implique una variación constante de los focos de atención (recursos y actividades), que fomente el intercambio y funcione con el motor del propio alumnado es, a mi entender, la clave para la docencia universitaria en estos tiempos.

La gamificación como recurso de base en esta nueva aula puede generar un ambiente propicio para la consecución de los objetivos didácticos en el ámbito propio de la Filología 
francesa. Esta dinámica puede funcionar como hilo conductor de cualquier materia en la que se creen diferentes actividades con herramientas digitales que fomenten la implicación directa del alumnado. Es aquí donde entra Twine, cuyas aplicaciones didácticas pueden ser de diverso tipo:

- En el aula de lengua francesa, la herramienta puede ser utilizada por parte del profesorado para crear un serious game sobre un punto de gramática en concreto, incluyendo la explicación teórica en las ramificaciones donde se incurrió en un error.

- En este mismo contexto, puede ser el alumnado el que cree varios serious games por grupos (cada uno para ejercitarse en un punto de gramática con explicaciones teóricas). Al final toda la clase juega y vota el mejor trabajo, que se verá premiado.

- También se puede ejercitar en el aula de lengua la expresión escrita a través de la creación de FI, especificando la necesidad de utilizar el corrector gramatical y marcando la pauta de acompañar la entrega del trabajo de un documento con los 5 principales errores que se han subsanado y su explicación gramatical.

- En el aula de literatura francesa, también se pueden crear serious games tanto del contexto histórico-filosófico de una obra literaria, como de la propia obra para que juegue el alumnado, o que sea éste el que proponga un Twine sobre una obra en concreto, con explicaciones teóricas. Ej. Sobre François Villon, cada grupo escoge un poema, lo analiza y después crea un Twine para ver si el resto entiende el análisis o si se equivoca, con votación y premio subsiguiente para el mejor trabajo.

- Otra aplicación, tanto en el aula de lengua como de literatura francesa, consiste en la creación de UD sobre un tema determinado, con hipervínculos a la bibliografía consultada.

Estas son sólo algunas de las aplicaciones didácticas que puede tener Twine. Nótese que, si la utilización de la herramienta es supervisada en clase por el personal docente, el alumnado resuelve fácilmente sus dudas y desaparecen los únicos problemas que tuvimos en el taller llevado a cabo durante el curso académico 2019-2020.

Ahora os invito a utilizarlo y a escribirme para contarme vuestras experiencias didácticas.

\section{Referencias bibliográficas}

Carreras, Carla. 2017. "Del homo ludens a la gamificación" in Quaderns de filosofia i ciència, nº4(1), 107-118.

Consejo de Europa. 2002. Marco Común Europeo de Referencia para las lenguas: apren- 
Anales de Filología Francesa, n. ${ }^{\circ}$ 29, 2021

LA CREACIÓN DE RELATOS DIGITALES NO LINEALES COMO HERRAMIENTA INTERCULTURAL EN EL...

dizaje, enseñanza, evaluación. Instituto Cervantes y Anaya: $<$ https://cvc.cervantes.es/ensenanza/biblioteca_ele/marco/cvc_mer.pdf $>$ [08/05/2021].

Contreras Espinosa, Ruth. 2016. "Juegos digitales y gamificación aplicados en el ámbito de la educación" in Revista Iberoamericana de Educación a Distancia, nº19 (2), 27-33: $<$ https://bit.ly/2Ib8HFW $>$ [04/05/2021].

Del-Moral, Ma Esther, Lourdes Villalustre \& María del Rosario Neira. 2016. "Relatos digitales: activando las competencias comunicativa, narrativa y digital en la formación inicial del profesorado" in Ocnos, $\mathrm{n}^{\circ} 15(1), 22-41$ : $<$ https://core.ac.uk/download/pdf/77077486. pdf> [30/04/2021].

FERnÁndez, Tania. 2017. Serious game: una metodología innovadora para la docencia de enfermería. Trabajo de Fin de Grado. Universidad de Navarra: $<$ https://academica-e.unavarra. es/xmlui/handle/2454/26853> [08/05/2021].

Huizinga, Johan. 1967 [1938]. Homo ludens. Milano, Giulio Einaudi.

KaAP, Karl M. 2012. The Gamification of Learning and Instruction: Game-based Methods and Strategies for Training and Education. San Francisco, Pfeiffer.

LABRANDE, Hugo. "Racontons une histoire ensemble: histoire et caractéristiques de la fiction interactive francophone": <http://hlabrande.fr/if/historyfrenchif/\#part8> [10/05/2021].

La Fontaine, Jean de. 2002. Fables. Paris, Le livre de poche.

Consejo de Europa. 2002. Marco común europeo de referencia para las lenguas: aprendizaje, enseñanza, evaluación. Instituto Cervantes y Anaya: $<$ https://cvc.cervantes.es/ensenanza/biblioteca_ele/marco/cvc_mer.pdf $>$ [08/05/2021].

MONTFORT, Nick. 2003. "Toward a theory of Interactive fiction": <https://nickm.com/if/ toward.html\#sec2> [15/04/2021].

Montgomery, Raymond Almiran \& Paul Granger. 1983. Las joyas perdidas de Nabooti. Elige tu propia aventura $n^{\circ} 2$. Barcelona, Timus Mas.

PAJARES Toska, Susana. 1997. "Las posibilidades de la narrativa intertextual" in ESPÉCULO. Revista de Estudios Literarios, 6: <http://www.ucm.es/OTROS/especulo/numero6/s_pajare.htm> [20/04/2021].

Rodríguez, Fernando y Raúl Santiago. 2015. Gamificación: Como motivar a tu alumnado y mejorar el clima en el aula. Innovación Educativa. Madrid, Digital-Text. Grupo Océano: <https://bit.ly/2js8uQG> [25/04/2021].

RYAN, Marie-Laure. 2005. "Peeling the Onion: Layers of Interactivity in Digital Text" in Interactivity of Digital Texts Conference, mayo, Münster: <http://www.marilaur.info/onion. $\mathrm{htm}>[08 / 05 / 2021]$.

VÁzquez Herrero, Jorge. 2019. Narrativas digitales de no ficción interactiva. Tesis doctoral, Universidad de Santiago de Compostela: <https://minerva.usc.es/xmlui/bitstream/handle/10347/20674/rep_1987.pdf?sequence=1\&isAllowed=y $>$ [29/04/2021]. 
Anales de Filología Francesa, n. ${ }^{\circ}$ 29, 2021

SILVIA HUESO FIBLA

Anexo 1. Análisis comparativo de los resultados obtenidos por el alumnado de 2019-

2020

\begin{tabular}{|c|c|c|c|c|c|c|c|}
\hline \multicolumn{2}{|l|}{ Ejercicio } & 1 & 2 & 3 & 4 & 5 & 6 \\
\hline \multicolumn{2}{|l|}{ Título } & $\begin{array}{l}\text { Scape } \\
\text { Room }\end{array}$ & $\begin{array}{l}\text { Il était } \\
\text { une fois... }\end{array}$ & $\begin{array}{l}\text { Île } \\
\text { déserte }\end{array}$ & $\begin{array}{l}\text { Persée et } \\
\text { Méduse }\end{array}$ & $\begin{array}{l}\text { Épilogue } \\
\text { Amalfitano }\end{array}$ & $\begin{array}{l}\text { La } \\
\text { boîte }\end{array}$ \\
\hline \multicolumn{2}{|l|}{ Tipología } & $\begin{array}{l}\text { Serious } \\
\text { Game }\end{array}$ & FI & FI/game & $\mathrm{FI} /$ game & FI & FI \\
\hline \multirow[t]{5}{*}{$\begin{array}{l}\text { Competencia } \\
\text { comunicativa }\end{array}$} & $\begin{array}{l}\text { Elaboración escrita de } \\
\text { la narración }\end{array}$ & & $\checkmark$ & & $\checkmark$ & & $\checkmark$ \\
\hline & $\begin{array}{ll}\text { Uso de vocabulario } \\
\text { adecuado }\end{array}$ & & $\checkmark$ & & $\checkmark$ & $\checkmark$ & $\checkmark$ \\
\hline & $\begin{array}{l}\text { Corrección gramatical } \\
\text { y ortográfica }\end{array}$ & & $\checkmark$ & & $\checkmark$ & $\boldsymbol{v}$ & $\checkmark$ \\
\hline & $\begin{array}{l}\text { Utilización correcta de } \\
\text { notaciones gráficas }\end{array}$ & $\checkmark$ & $\checkmark$ & $\checkmark$ & & $v$ & $\checkmark$ \\
\hline & $\begin{array}{ll}\begin{array}{l}\text { Registro } \\
\text { adecuado }\end{array} & \text { lingüístico } \\
\end{array}$ & $\checkmark$ & $\checkmark$ & $\checkmark$ & $\checkmark$ & $\checkmark$ & $v$ \\
\hline \multirow[t]{5}{*}{$\begin{array}{l}\text { Competencia } \\
\text { narrativa }\end{array}$} & $\begin{array}{l}\text { Inclusión armónica de } \\
\text { los puntos de inflexión } \\
\text { del relato }\end{array}$ & & $\checkmark$ & $\checkmark$ & $\checkmark$ & & $\checkmark$ \\
\hline & Coherencia interna & $\checkmark$ & $\checkmark$ & & $\checkmark$ & & $\checkmark$ \\
\hline & $\begin{array}{l}\text { Construcción de perso- } \\
\text { najes }\end{array}$ & & $\checkmark$ & & & & \\
\hline & $\begin{array}{l}\text { Resolución creativa de } \\
\text { la trama }\end{array}$ & & & & & & $\checkmark$ \\
\hline & $\begin{array}{l}\text { Intención comunicati- } \\
\text { va visible }\end{array}$ & $\checkmark$ & $\checkmark$ & $\checkmark$ & $\checkmark$ & & \\
\hline \multirow[t]{5}{*}{$\begin{array}{l}\text { Competencia } \\
\text { digital }\end{array}$} & $\begin{array}{l}\text { Uso adecuado de las } \\
\text { aplicaciones informáti- } \\
\text { cas y sus herramientas }\end{array}$ & $\checkmark$ & $\checkmark$ & $\checkmark$ & $\checkmark$ & $\checkmark$ & $\checkmark$ \\
\hline & $\begin{array}{l}\text { Estructuración cuidada } \\
\text { del proyecto }\end{array}$ & $\checkmark$ & $\checkmark$ & & $\checkmark$ & & $\checkmark$ \\
\hline & $\begin{array}{l}\text { Cohesión del sonido } \\
\text { con la narración }\end{array}$ & $\checkmark$ & & & & $\checkmark$ & $v$ \\
\hline & $\begin{array}{l}\text { Selección adecuada de } \\
\text { imágenes }\end{array}$ & $\checkmark$ & $\checkmark$ & $\checkmark$ & $\checkmark$ & $\checkmark$ & $\checkmark$ \\
\hline & $\begin{array}{l}\text { Publicación del proyec- } \\
\text { to en libre acceso }\end{array}$ & $\checkmark$ & & $\checkmark$ & & $\checkmark$ & $\checkmark$ \\
\hline
\end{tabular}


